\title{
An empirical determination of the whole-life cost of FO-based open- loop wastewater reclamation technologies
}

Rem Jalab ${ }^{\mathrm{a}}$, Abdelrahman M Awad ${ }^{\mathrm{a}}$, Mustafa S Nassera ${ }^{\mathrm{a}^{*}}$, Joel Minier-Matar ${ }^{\mathrm{b}}$, Samer Adham ${ }^{\mathrm{b}}$, Simon J Judd ${ }^{*}$

${ }^{a}$ Gas Processing Centre, College of Engineering, Qatar University, Doha, Qatar

${ }^{\mathrm{b}}$ ConocoPhillips Global Water Sustainability Centre, Qatar Science \& Technology Park, Doha, Qatar+

${ }^{\mathrm{c}}$ Cranfield Water Science Institute, Cranfield University, Beds, UK.

*Corresponding authors: Tel.: +44 7747 878944, e-mail s.j.judd@cranfield.ac.uk; Tel.: +974 50396072, e-mail: m.nasser@qu.edu.qa

\begin{abstract}
Over the past 5-10 years it has become apparent that the significant energy benefit provided by forward osmosis (FO) for desalination arises only when direct recovery of the permeate product from the solution used to transfer the water through the membrane (the draw solution) is obviated. These circumstances occur specifically when wastewater purification is combined with saline water desalination. It has been suggested that, for such an "open loop" system, the FO technology offers a lower-cost water reclamation option than the conventional process based on reverse osmosis (RO).
\end{abstract}

An analysis is presented of the costs incurred by this combined treatment objective. Three process schemes are considered combining the FO or RO technologies with membrane bioreactors (MBRs): MBR-RO, MBR-FO-RO and osmotic MBR (OMBR)-RO. Calculation of the normalised net present value (NPV/permeate flow) proceeded through developing a series of empirical equations based on available individual capital and operating cost data. Cost curves (cost vs. flow capacity) were generated for each option using literature MBR and RO data and making appropriate assumptions regarding the design and operation of the novel FO and OMBR technologies.

Calculations revealed the MBR-FO-RO and OMBR-RO schemes to respectively offer a $\sim 20 \%$ and $\sim 30 \%$ NPV benefit over the classical MBR-RO scheme at a permeate flow of $10,000 \mathrm{~m}^{3} \cdot \mathrm{d}^{-1}$, provided the respective schemes are applied to high and low salinity wastewaters. Outcomes are highly sensitive to the FO or OMBR flux sustained: the relative NPV benefit (compared to the classical system) of the OMBR-RO scheme declined from $30 \%$ to $4 \%$ on halving the OMBR flux from a value of $6 \mathrm{~L} \cdot \mathrm{m}^{-2} \cdot \mathrm{h}^{-1}$.

Keywords: Forward osmosis; cost; osmotic MBR; reverse osmosis; wastewater reuse

\section{Introduction}

Forward osmosis (FO) is an emerging water purification technology based on naturally occurring osmosis, the diffusion of a solvent - normally water - through a perm-selective membrane barrier from a low to high electrolyte (or salt) solution concentration. In the FO process the more-concentrated solution is termed the "draw" solution (DS); the DS acts to transfer the water (permeate) from the low-concentration solution (the feedwater). To recover the permeated water a further step is required to separate the permeate from the draw solution (DS) electrolyte, normally reverse osmosis (RO), which may then also permit DS reuse.

It is widely recognised that the DS recovery represents the greatest challenge to the technical and economic feasibility of the FO process (Chekli et al., 2016; Johnson et al., 2018). It has, for example, been calculated that recovery of the permeate and draw solution incurs costs 65$140 \%$ higher than conventional RO for agricultural or diluted mining wastewater reclamation (Corzo et al., 2018; Kim et al., 2017). FO has nonetheless been mooted as an alternative to conventional demineralisation by RO for wastewater treatment and reclamation (Ansari et al., 2017; Valladares Linares et al., 2014). It is claimed that the technology can be energetically favoured when a highly saline water source requires desalination in conjunction with the wastewater purification (Cath et al., 2010; Choi et al., 2015; Hancock et al., 2012; Wan and 
Chung, 2018; Valladares Linares et al., 2014; Yangali-Quintanilla et al., 2011). For such an "open loop" system, as compared with the classical "closed loop" system, the process is configured so that the FO stage acts to dilute the saline feedwater upstream of an RO stage, reducing its osmotic pressure and so the energy consumption of the RO step. The FO step is fed with the low-salinity wastewater, producing a concentrated wastewater waste stream along with high-salinity water used as the DS (Fig. 1).

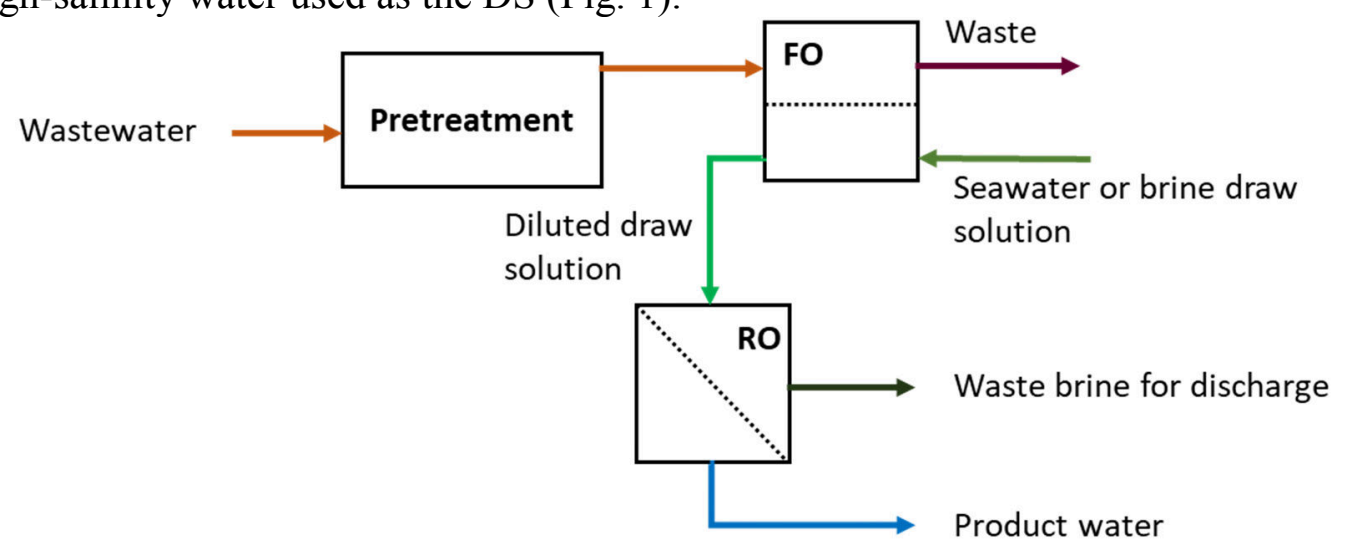

Figure 1. "Open-loop" combined wastewater reclamation and desalination

As with all membrane processes, the FO technology requires amelioration of membrane surface fouling (Nguyen et al., 2019; Siddiqui et al., 2018; Xie et al., 2017). For wastewater reclamation duties a widely accepted state-of-the-art RO pretreatment technology for fouling suppression is the membrane bioreactor (MBR), with a number of pilot and full-scale demonstration studies reported over the past 20 years (Blanco et al., 2016; Côté et al., 1997; De Jager et al., 2014; Dialynas and Diamadopoulos, 2009; Farias et al., 2014; Gündoğdu et al., 2018; Lawrence et al., 2003). The MBR-RO process (Fig. 2a) is an established option for small-scale industrial applications, and has been implemented at full-scale for around 20 years (Judd, 2014).

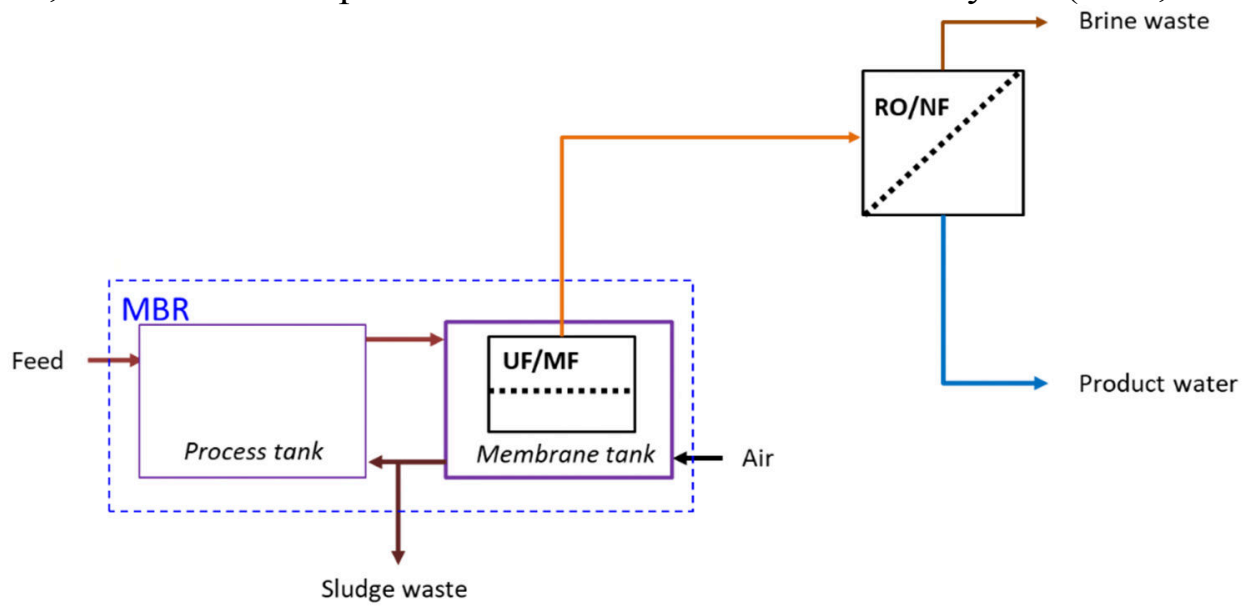

(a) 


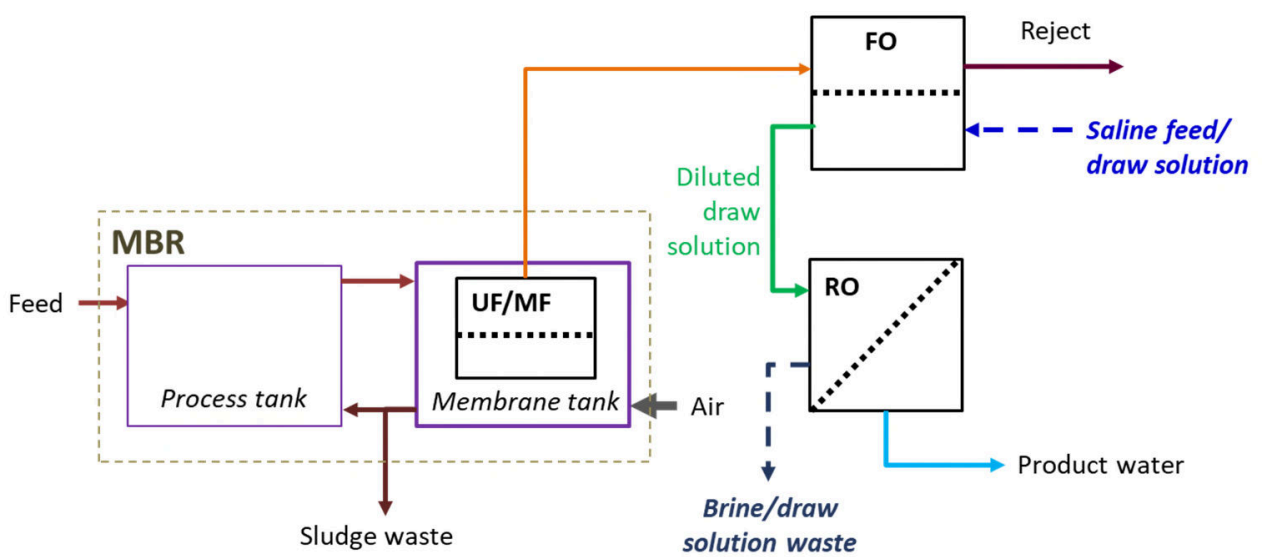

(b)

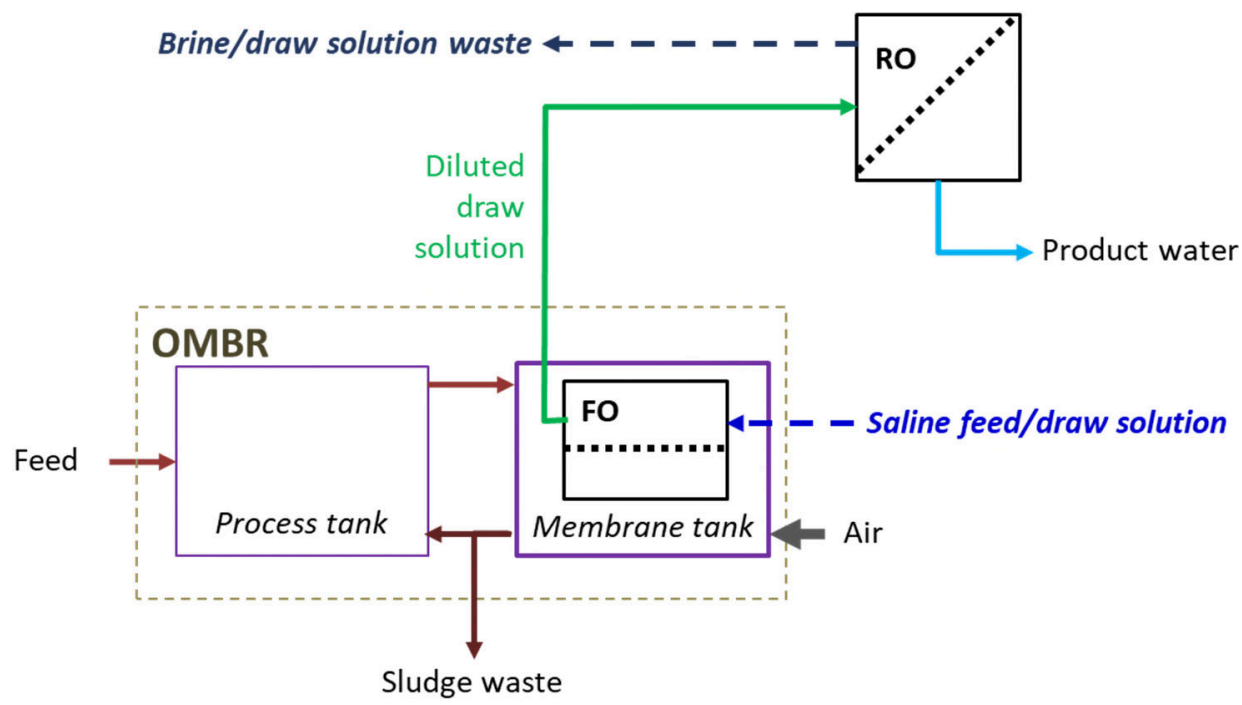

(c)

Figure 2. Process alternatives for wastewater reclamation: (a) classical MBR-RO, (b) open-loop MBR-FO, and (c) open-loop OMBR.

FO may be employed either downstream of the MBR, i.e. as an alternative to the RO desalination step (Fig. 2b), or integrated with the MBR as an osmotic membrane bioreactor (OMBR, Fig. 2c). The OMBR technology offers the most obvious advantage over the classical MBR-RO approach of obviating the desalination step by combining desalination and biological treatment in a single stage. However, as with the standard FO process, OMBR appears to become cost-effective only when the biological wastewater treatment is combined with saline water desalination (Blandin et al., 2018) in an open-loop system.

Whilst there have been many papers examining various attributes of FO technology, these have commonly focused on topics such as the DS chemical and its recovery (Alejo et al., 2017; Cai and $\mathrm{Hu}, 2016$; Ge et al., 2017; Johnson et al., 2018), membrane fouling propensity (Bogler et al., 2017; She et al., 2016), and membrane material development (Suwaileh et al., 2018; Xu et al., 2017). Limited attention has been paid to the whole-life costs of the various FO-based process options for wastewater reclamation specifically, compared to the conventional MBRRO option. Of the few studies which have considered open-loop FO systems (Blandin et al., 2015; Teusner et al., 2017), outcomes suggest a small economic benefit.

In view of the above, the current paper provides an assessment of the economic feasibility of FO for wastewater treatment/reclamation through determination of the net present value (NPV) 
from the capital expenditure (CAPEX) and operating expenditure (OPEX) contributions, the latter arising primarily from the specific energy demand (SED) in $\mathrm{kWh} . \mathrm{m}^{-3}$ and critical component life. The three treatment options depicted in Figure 2 are considered, namely:

1. Classical treatment by membrane bioreactor technology followed by reverse osmosis (MBR-RO), Fig. 2a;

2. Novel treatment by an open-loop MBR-FO, Fig. 2b;

3. Novel treatment using an open-loop osmotic membrane bioreactor (OMBR), Fig 2c.

The empirical analysis proceeds by using published cost and O\&M data from existing full-scale MBR and RO installations, these then being used to infer the cost of a full-scale FO and OMBR installations.

\section{$2 \quad$ Materials and methods}

\subsection{Information and data sources}

The analysis captured or made use of:

a) published CAPEX data and data trends (specifically cost as function of flow rate, or "cost curves") from existing installations,

b) classical analytical expressions for (i) aeration and pumping energy demand, and (ii) process biological aeration for both the MBR and OMBR, and

c) proprietary CAD software for determination of energy demand and chemicals consumption for both the RO and FO technologies.

A feedwater composition typical for medium-strength municipal wastewater (Tchobanoglous et al., 2003) was selected, supplemented with elevated hardness, alkalinity and salinity levels (Table 1). The impact of salinity on RO energy demand was determined over a $20-7500 \mathrm{mg} / \mathrm{L}$ sodium concentration range, balancing with chloride. Process biology energy demand was calculated based on classical biochemical stoichiometry (Judd, 2014; Tchobanoglous et al., 2003) for absolute COD and TKN removals of 500 and $40 \mathrm{mg} / \mathrm{L}$ respectively. Labour and waste disposal costs were both ignored: it was assumed that no significant differences in staffing levels existed between the three options, and that waste disposal costs were also similar.

\begin{tabular}{l|l} 
Table $1 . \quad$ Feedwater quality \\
\hline Parameter & Concn. $\mathbf{m g} / \mathbf{L}$ \\
\hline Total dissolved solids & $500-5000$ \\
Chemical oxygen demand removed $(\Delta \mathrm{COD})$ & $500-2500$ \\
Total Kjeldal nitrogen removed $(\Delta \mathrm{TKN})$ & 40 \\
Nitrate & 0 \\
Hardness (as $\left.\mathrm{CaCO}_{3}\right)$ & 180 \\
Alkalinity $\left(\right.$ as $\left.\mathrm{CaCO}_{3}\right)$ & 150 \\
\hline
\end{tabular}

\subsection{Assumptions}

Calculations proceeded through determining CAPEX as a function of flow capacity for all four technologies (MBR, OMBR, RO and FO) using the data trends of Loutatidou et al. (2014) for seawater (SW) and brackish water (BW) RO desalination plants. OPEX was calculated as a function of the membrane flux and the TDS and COD concentrations for the RO and MBR respectively. In the absence of available CAPEX data for the FO and OMBR technologies, a number of key assumptions were made in adapting the available RO and MBR data: 
A. SWRO and BWRO installations were assumed to operate respectively above and below a threshold pressure of 15 bar. This threshold pressure was used to differentiate the BWRO and SWRO CAPEX curve data sets provided by Loutatidou et al., 2014.

B. FO CAPEX was equated to that of a BWRO with FO membrane elements replacing the RO ones, the membrane area being adjusted according to the design flux. The FO plant CAPEX was then determined as:

$$
L_{C, F O}=L_{C, B W R O}-L_{M, R O} A_{R O}+L_{M, F O} A_{F O}
$$

where $A$ refers to installation membrane area, given by the ratio of the permeate flow $\left(Q_{p}\right)$ to the flux $(J)$, and $L_{M}$ to the membrane cost per unit area.

C. The OMBR CAPEX was equated to that of an MBR with FO membrane elements replacing the conventional microfiltration/ultrafiltration ones, the OMBR CAPEX being given by:

$$
L_{C, O M B R}=L_{C, M B R}-L_{M, M B R} A_{M B R}+L_{M, O M B R} A_{O M B R}
$$

$A$ and $L_{M}$ being analogous to the corresponding parameters for the FO case (Equation 1).

D. The SED of FO was equated to that of the equivalent BWRO array operating at zero osmotic pressure and a reduced flux appropriate to the FO. This corresponds to the energy associated with pumping through the membrane channels and pipework, as determined from the RO CAD software (Section 2.4.2).

E. The SED of the OMBR was equated to that determined for operation of the MBR, based on the OMBR flux, with the air scour rate in $\mathrm{Nm}^{3} \cdot \mathrm{h}^{-1}$ air per $\mathrm{m}^{-2}$ membrane area assumed to be the same for both technologies.

F. The MBR step was assumed to provide sufficient pretreatment for sustainable operation of the FO at the stipulated net flux for the FO-MBR option, and the OMBR assumed to need no further pretreatment to that required for the MBR-RO and MBR-FO options.

A CAPEX benefit of FO over RO associated with the lower-pressure operation thus exists at feed pressures above $\sim 15$ bar, since below this threshold the same low-pressure materials (e.g. fibre-reinforced plastic) and equipment can be used for both technologies. Above this threshold higher-grade materials (e.g. 316L stainless steel) must be used for RO, whereas the FO technology - always operating at low pressure - can always employ the less expensive materials. Below the threshold the CAPEX difference between RO and FO installations relates only to the difference in the total cost of the membrane modules.

The MBR-FO-RO scheme yields an energy benefit associated with dilution of the RO saline feed by the FO (Fig. 2b), translating to a proportional OPEX benefit $(\triangle \mathrm{OPEX}=\mathrm{f}(C))$. However, this benefit is only obtained by increasing the capacity of the RO desalination step, which incurs a CAPEX penalty $(\triangle \mathrm{CAPEX}=\mathrm{f}(Q))$. Both of these cost components can be normalised against the permeate volume generated over the plant life as part of the NPV determination.

The MBR and OMBR technologies have a process biological operational limit imposed by the feedwater salinity; biological activity is adversely affected by high salinities. In the case of the OMBR salinity accumulates in the bioreactor as a result of its rejection by the membrane, imposing an upper limit on the combined feedwater salinity and permeate recovery. The analysis was based on a recovery of $95 \%$ for both the OMBR and MBR.

An immersed MBR/OMBR configuration was assumed throughout. A recent study (Judd and Turan, 2018) has indicated the immersed configuration (iMBR) to be economically favoured at flow capacities above $7,000 \mathrm{~m}^{3} \cdot \mathrm{d}^{-1}$. For the OMBR the sidestream configuration offers no advantage, since the key facet of low-pressure permeation offered by the OMBR is lost for the inherently high-pressure sidestream system. 
Historical CAPEX data (Loutatidou et al., 2014) suggests that the CAPEX of RO installations decreased between the years 2000 and 2012. This trend was extrapolated to 2019 to obtain the 2019 CAPEX figures for the RO and FO plants. The subsequent NPV calculations nonetheless assumed a discount factor $\mathbf{D}$ of $2 \%$, and were based on the approach of Verrecht et al., 2010.

\subsection{MBR and OMBR costs}

The MBR and OMBR were assumed to be based on the same membrane configuration with air scour, backwashing and chemical cleaning as appropriate to sustain membrane permeability. As such differences in CAPEX between the two technologies are ostensibly due to the specific cost $\left(\$ . \mathrm{m}^{-2}\right)$ and total area requirement of the membrane, the area being inversely proportional to the flux. Membrane costs, included in Table 2, were captured from suppliers' information.

\subsubsection{CAPEX}

Published MBR CAPEX information includes cost curves interpreted from data provided by Itokawa et al., 2014 and Iglesias et al., 2017 for Japanese and Spanish full-scale installations respectively, and costs determined from the commercial software CAPDETWorks (Cashman and Mosely, 2016). CAPEX values at specific flow capacities have been provided by several authors (Brepols et al., 2010; DeCarolis et al., 2007; Fleischer et al., 2010; Wozniak, 2012; Young et al., 2013). All captured data was normalised against permeate flow rate $\left(Q_{p}\right)$ to give the specific CAPEX $L_{C}$ in $\mathrm{k} \$$ per $\mathrm{m}^{3} . \mathrm{d}^{-1}$.

\subsubsection{OPEX}

MBR OPEX was determined through:

(a) capture of data relating to design and operation of a representative iMBRs treating municipal wastewater, including membrane module costs, chemical usage and costs, and membrane life (Table 2), and

(b) calculation of the SED in $\mathrm{kWh}$ per $\mathrm{m}^{3}$ permeate from known analytical equations (Table 3 ).

Table 2. MBR and OMBR operational process parameter base values

\begin{tabular}{|c|c|c|}
\hline Parameter & Symbol & Value(s): Base, range \\
\hline Oxygen content of air, $\%$ & $C_{A}^{\prime}$ & $21 \%$ \\
\hline Mass consumption of oxygen, g. $\mathrm{m}^{-3}$ & $D_{O 2}$ & Calculated \\
\hline SED, biological aeration, $\mathrm{kWh} . \mathrm{m}^{-3}$ & $E_{A, b i o}$ & Calculated \\
\hline SED, membrane aeration (air), kWh. $\mathrm{Nm}^{-3}$ & $E_{A, m}^{\prime}{ }^{\mathrm{d}}$ & Calculated \\
\hline SED, membrane aeration (permeate), kWh. $\mathrm{m}^{-3}$ & $E_{A, m} \mathrm{e}^{\mathrm{e}}$ & Calculated \\
\hline SED, membrane permeation, kWh. $\mathrm{m}^{-3}$ & $E_{L, m}^{\mathrm{b}}$ & 0.008 \\
\hline SED, sludge pumping, kWh.m ${ }^{-3}$ & $E_{L, \text { sludge }}^{\mathrm{c}}$ & $0.016 . R$ \\
\hline Depth of aerator in tank, $m$ & $h$ & 5 \\
\hline Specific capital cost, $\mathrm{k} \$ /\left(\mathrm{m}^{3} \cdot \mathrm{h}^{-1}\right)$ & $L_{C}$ & Calculated \\
\hline Permeate net flux, L. $\mathrm{m}^{-2} \cdot \mathrm{h}^{-1}$ & $J_{M B R}, J_{O M B R}$ & $15^{\mathrm{f}}-22(\mathrm{MBR}), 4$ (OMBR) \\
\hline Chemicals consumption costs, $\$ \cdot \mathrm{m}^{-3}$ permeate & $L_{\text {Chem, } M B R}$ & $0.01^{\mathrm{g}}$ \\
\hline Electricity supply cost, $\$ . \mathrm{kWh}^{-1}$ & $L_{E}$ & 0.1 \\
\hline Membrane cost, $\$ . \mathrm{m}^{-2}$ membrane area & $L_{M, M B R}, L_{M, O M B R}$ & 30 (MBR), 50 (OMBR) \\
\hline Operating cost, $\$ . \mathrm{m}^{-3}$ permeate & $L_{O}$ & Calculated \\
\hline Oxygen transfer efficiency per unit depth, $\mathrm{m}^{-1}$ & OTE & 0.045 \\
\hline Permeate flow rate, $\mathrm{m}^{3} \cdot \mathrm{h}^{-1}$ & $Q_{P}$ & Variable \\
\hline Membrane-biological process tank recycle ratio, - & $R$ & 5 \\
\hline $\mathrm{SAD}$, membrane scouring, $\mathrm{Nm}^{3} \cdot \mathrm{m}^{-2} \cdot \mathrm{h}^{-1}$ & $S A D_{m}{ }^{\mathrm{a}}$ & 0.35 \\
\hline Change in $\mathrm{COD}, \mathrm{TKN}, \mathrm{NO}_{3}{ }^{-}$concs., g. $\mathrm{m}^{-3}$ & $\Delta S_{C O D}, \Delta S_{T K N}, \Delta S_{\text {Nitrate }}$ & $500,40,0$ \\
\hline Membrane life, hrs & $t_{M B R}, t_{O M B R}$ & 70080,70080 \\
\hline MLSS concn., process, membrane tanks, $\mathrm{kg} . \mathrm{m}^{-3}$ & $X, X_{m}$ & 8,10 \\
\hline Observed sludge yield, kgSS.kgCOD ${ }^{-1}$ & $Y_{o b s}$ & 0.35 \\
\hline Mass transfer correction factors & $\beta, \gamma$ & $0.95,0.89$ \\
\hline
\end{tabular}




\begin{tabular}{l|ll}
\hline Biomass COD, TKN content, kg.kgSS & -1 \\
Total pumping electrical energy efficiency, - & $\lambda_{C O D}, \lambda_{T K N}$ & $1.1,0.095$ \\
Air density, g.m ${ }^{-3}$ & $\varepsilon_{t o t}$ & $65 \%$ \\
Conversion (permeate/feed flow) & $\rho_{A}$ & 1.23 \\
\hline
\end{tabular}

SAD Specific aeration demand; SED specific energy demand; ${ }^{a}$ Air flow rate/membrane area for air scour; ${ }^{b}$ Pump power/permeate flow rate; ${ }^{\mathrm{C}}$ Pump power/sludge flow rate; ${ }^{\mathrm{d} B}$ lower power/air flow rate; ${ }^{\mathrm{e}}$ Blower power/permeate flow rate; ${ }^{\text {fLower }}$ limit at high TDS, upper limit at low TDS; ' ${ }^{B}$ Based on sodium hypochlorite and citric acid costs and usage (Judd, 2014). Calculation of parameters is as indicated in Table 3.

The baseline net flux $(J)$, air-scour specific aeration demand $\left(S A D_{m}, \mathrm{Nm}^{3} \cdot \mathrm{h}^{-1}\right.$ air flow per $\mathrm{m}^{2}$ membrane area), and permeation energy $\left(E_{L, m}\right)$ values were based on that typical of installed full-scale iMBRs (Judd, 2016). The OMBR flux was based on reported values (Holloway et al., 2015, 2014; Liu et al., 2017; Lu and He, 2015; Luo et al., 2016). The omission of labour costs means that OPEX is not a significant function of flow capacity (Judd and Turan, 2019).

Table 3. MBR and OMBR OPEX-related equations (adapted from (Judd, 2014, 2017; Judd and Turan, 2019))

\begin{tabular}{|c|c|c|}
\hline Parameter & Symbol & Equation \\
\hline \multicolumn{3}{|l|}{ Membrane } \\
\hline SED, kWh.m $\mathrm{m}^{-3}$ & $E_{m}$ & $1000 E_{A, m}^{\prime} S A D_{m} / J+E_{L, \text { sludge }, i} R_{i}+E_{L, m, i}$ \\
\hline \multicolumn{3}{|c|}{ Process biology (assuming MLE process denitrification) } \\
\hline Oxygen demand, kg.m $\mathrm{m}^{-3}$ & $\mathrm{D}_{\mathrm{O} 2}$ & $\Delta S_{C O D}\left(1-\lambda_{C O D} Y_{o b s}-1.71 \lambda_{T K N} Y_{o b s}\right)+1.71 \Delta S_{T K N}-2.86 \Delta S_{\text {Nitrate }}$ \\
\hline $\mathrm{SAD}, \mathrm{Nm}^{3} \cdot \mathrm{m}^{-2} \cdot \mathrm{h}^{-1}$ & $S A D_{b i o}{ }^{\mathrm{a}}$ & 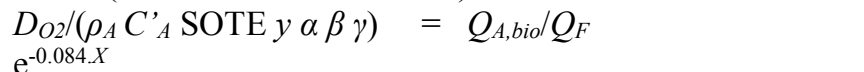 \\
\hline SED, aeration, kWh.Nm ${ }^{-3}$ & $E_{A}^{\prime}$ & $k\left((0.0943 h+1)^{0.283}-1\right) / \varepsilon_{\text {tot }} \quad$ where $k=0.107 \mathrm{kWh} . \mathrm{Nm}^{-3}$ \\
\hline $\begin{array}{l}\text { SED, permeate, } \mathrm{kWh} \cdot \mathrm{m}^{-3} \\
\text { OPEX }\end{array}$ & $E_{A, b i o}$ & $E_{A}^{\prime} S A D_{b i o}$ \\
\hline Cost $\mathrm{m}^{-3}$ permeate, $\$ . \mathrm{m}^{-3}$ & $L_{O, M B R}$ & $L_{E}\left(E_{m}+E_{A, b i o}\right)+L_{M} /(J t)+L_{C}+L_{W}$ \\
\hline
\end{tabular}

\section{$2.4 \quad$ RO and FO costs}

\subsubsection{CAPEX}

RO CAPEX data was extracted from the comprehensive data set provided for installed, fullscale brackish and seawater RO desalination plants (Loutatidou et al., 2014). This data set refers to CAPEX trends based on Engineering, Procurement \& Construction (EPC) contracts for RO installations in the GCC and Southern European geographical regions. It was assumed that the civil engineering (CE) cost component included in the MBR cost data applied to the complete installation, i.e. that no supplementary $\mathrm{CE}$ cost was required for either the RO or FO components.

\subsubsection{OPEX}

RO OPEX was calculated using the proprietary RO CAD design tool ROPRO (Koch Membrane Systems, Wilmington, MA) to estimate the SED and the $\mathrm{pH}$-adjustment chemical (sulfuric acid) consumption rate for a commercial BW or SW membrane ( $8822 \mathrm{HR} 400$ and 8822 XR400, Koch Membrane Systems, Wilmington, MA) based on a two-stage 2:1 RO array (i.e. yielding a conversion of $75 \%$ ). The required acid dose was determined based on a Langelier Saturation Index (LSI) of 0-0.01 for the pretreated water. Required doses and costs of other specialist RO chemicals (antiscalants and membrane cleaning) were estimated from suppliers' information and published literature data (Korenak et al., 2019; Shahabi et al., 2015; Valladares Linares et al., 2016). FO OPEX was estimated using the same ROPRO design tool, based on the lower design flux low-pressure operation (Table 4), the FO flux estimated from reported pilot-scale studies (Awad et al., 2019). The overall specific OPEX, $L_{O, R O}$, is then analogous to that of an MBR but without the process biological energy component $\left(E_{A, b i o}\right)$.

Table 4. RO and FO operational process parameter base values 


\begin{tabular}{l|llcc}
\hline Parameter & Symbol & Units & RO & FO \\
\hline Permeate net flux, $\mathrm{L}^{-\mathrm{m}^{-2}} \cdot \mathrm{h}^{-1}$ & $J_{R O}, J_{F O}$ & $\mathrm{LMH}$ & 20 & 6 \\
Process conversion & $\Theta_{R O}, \Theta_{F O}$ & - & $75 \%$ & $75 \%$ \\
Membrane life, y & $t_{R O}, t_{F O}$ & $\mathrm{hrs}$ & 43800 & 70080 \\
Membrane cost & $L_{M, R O}, L_{M, F O}$ & $\$ . \mathrm{m}^{-2}$ & 13 & 50 \\
Sulphuric acid cost (98\% stock) & $L_{A c i d}$ & $\$ . \mathrm{tacid}^{-2}$ & \multicolumn{2}{c}{270} \\
Antiscalants dose costs & $L_{\text {Antiscalant }}$ & $\$ \mathrm{~m}^{3}$ permeate & \multicolumn{2}{c}{0.011} \\
\multicolumn{2}{l}{ Target Langelier Scaling Index value } & LSI & - & \multicolumn{2}{c}{0.0 .01} \\
\hline \multicolumn{2}{|l}{ All values of other relevant parameters as given in Table 3 }
\end{tabular}

\section{Results and discussion}

\subsection{MBR and OMBR costs}

\subsubsection{CAPEX}

The specific CAPEX, $L_{C, M B R}$ in $\mathrm{k} \$$ per $\mathrm{m}^{3} . \mathrm{d}^{-1}$, was determined for each of the reported CAPEX: $Q_{P}$ data sets (Cashman and Mosely, 2016; Iglesias et al., 2017; Itokawa et al., 2014) over two decades of flow (500-50,000 $\left.\mathrm{m}^{3} \cdot \mathrm{d}^{-1}\right)$. Each were fitted to a power law relationship (Fig. 3):

$$
L_{C, M B R}=m Q_{P}{ }^{n}
$$

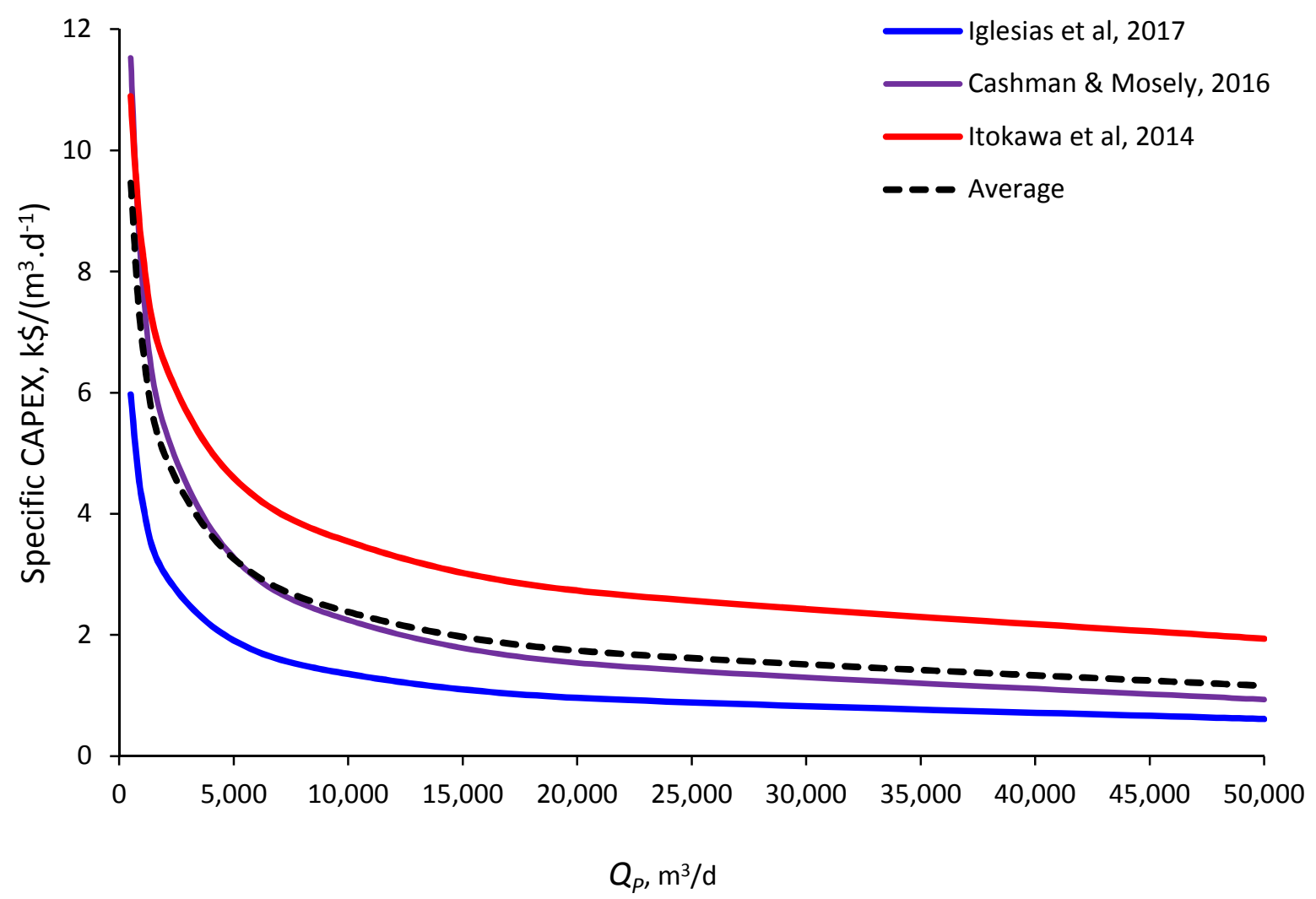

Figure 3. Specific iMBR CAPEX (corrected to 2019 USD) vs flow capacity based on outcomes of three studies.

albeit with a high degree of data scatter in the case of the Itokawa et al., 2014 data (Table 5). The disparity between the three data sets may either reflect regional differences or else result from the methodology used. The average of the three curves is very close to that interpolated from the study outputs of Cashman and Mosely, 2016 (Fig. 3, Table 5): 
Table 5. Specific CAPEX correlations from published data, 2019 US\$ $\mathrm{k} \$$ per $\mathrm{m}^{3} \cdot \mathrm{d}^{-1}$

\begin{tabular}{lccc}
\hline Source & $\begin{array}{c}\text { Coefficient, } \\
\boldsymbol{m}^{\mathbf{1}}\end{array}$ & Exponent, $\boldsymbol{n}^{\mathbf{1}}$ & $\mathbf{R}^{\mathbf{2}}$ \\
\hline (Iglesias et al., 2017) & 129 & -0.495 & 0.94 \\
(Itokawa et al., 2014) & 112 & -0.375 & 0.6 \\
(Cashman and Mosely, 2016) & 343 & -0.546 & - \\
Average & $\mathbf{1 6 7}$ & $\mathbf{- 0 . 4 6 2}$ & - \\
${ }^{1}$ Constants in Equation 1 & & & \\
\multicolumn{1}{c}{$L_{C, M B R}=167 Q_{P}^{-0.462}$} & & &
\end{tabular}

According to this relationship, the specific CAPEX range between permeate flows of 3,800 and $19,000 \mathrm{~m}^{3} \cdot \mathrm{d}^{-1}$ is $\$ 1.76$ to $3.71 \mathrm{k} \$$ per $\mathrm{m}^{3} \cdot \mathrm{d}^{-1}$, which is in reasonable agreement with the range of 2.03-3.09 $\mathrm{k} \$$ per $\mathrm{m}^{3} . \mathrm{d}^{-1}$ reported across four other studies (Brepols et al., 2010; DeCarolis et al., 2007; Wozniak, 2012; Young et al., 2013).

For the immersed OMBR the CAPEX can be estimated with reference to the contribution of the membrane to the overall plant CAPEX. Based on assumed membrane costs of 30 and 50 $\$ . \mathrm{m}^{-2}$ for the MBR and OMBR respectively (Table 2), coupled with assumed net average fluxes of 20 and 6 LMH (Table 4), the specific CAPEX trend can be fitted to the power law:

$$
L_{C, O M B R}=116 Q_{P}^{-0.386}
$$

It is further possible to recalculate the MBR CAPEX curve for a design flux of $15 \mathrm{LMH}$, appropriate for high TDS feedwaters which form less filterable mixed liquors, by adjusting the membrane area accordingly:

$$
L_{C, M B R, \text { high TDS }}=139 Q_{P}^{-0.424}
$$

\subsubsection{MBR and OMBR OPEX}

The MBR specific OPEX $L_{O, M B R}$ in $\$ . \mathrm{m}^{-3}$ permeate calculated from the base values listed in Table 2 and the relationships given in Table 3 can be expressed as a function of the flux $J_{M B R}$ (in $\left.\mathrm{L} \cdot \mathrm{m}^{-2} \cdot \mathrm{h}^{-1}\right)$ and the specific aeration demand $S A D_{m}\left(\mathrm{Nm}^{3} \cdot \mathrm{L}^{-1} \cdot \mathrm{m}^{-2}\right)$ for membrane scouring:

$$
L_{O, M B R}=2.21 S A D_{m} / J+0.0164+L_{E} E_{A, b i o}
$$

where $L_{E}$ is the cost of electrical energy supply in $\mathrm{kWh} \cdot \mathrm{m}^{-3}$ (Table 2) and $E_{A, b i o}$ the SED of the process biological tank (determined from the process biology relationships, Table 3). Equation 7 also applies to the OMBR OPEX, if it assumed that the cleaning requirements are similar and the air scour employed is the same. Using the base values for the feedwater quality given in Table 1:

$$
E_{A, b i o l}=5.08 \times 10^{-4} \mathrm{COD}+0.05
$$

\subsection{RO and FO costs}

\subsubsection{CAPEX}

The data of Loutatidou et al. (2014) yields the following specific CAPEX correlations for saline and brackish water RO installations:

$$
L_{C, S W R O}=5.16 Q_{p, R O}{ }^{-0.0654}
$$




$$
L_{C, B W R O}=2.42 Q_{p, R O^{-0.0804}}
$$

Based on the assumptions given in Section 2.2, the FO plant CAPEX can be estimated from the BWRO CAPEX, assuming the RO elements to be replaced with sufficient FO elements to provide the same product flow capacity. This then yields the relationship:

$$
L_{C, F O}=2.41 Q_{p, F O^{-0.0502}}
$$

Published FO CAPEX data is scarce, but the $L_{C, F O}$ value of $1.35 \mathrm{k} \$$ per $\mathrm{m}^{3} \cdot \mathrm{d}^{-1}$ calculated for a flow $Q_{p, F O}$ of $100,000 \mathrm{~m}^{3} . \mathrm{d}^{-1}$ from Equation (9) is somewhat higher than the value of 0.79 determined by Valladares Linares et al., 2016. However, the respective CAPEX ratio values $\left(L_{C, F O} / L_{C, S W R O}\right)$ of 0.65 (Valladares Linares et al., 2016) cf. 0.53 (this study) at this flow capacity are in reasonable agreement. Difference in absolute CAPEX values can be attributed to the low blanket EPC cost of $\$ 1.21 \mathrm{k} \$$ per $\mathrm{m}^{3} . \mathrm{d}^{-1}$ assigned to SWRO by Valladares Linares et al based on a 2007 study (Fritzmann et al., 2007), about half the corresponding value determined in the current study.

\subsubsection{OPEX}

The commercial RO CAD package computed data for the total power consumption, the maximum operating pressure (i.e. the feed pressure), and the chemical consumption rate (Table 6 ). From these data the average chemical dosing cost, $E_{C, R O}$, and the instantaneous OPEX $L^{\prime}{ }_{O, R O}$ was calculated for the range of ion compositions indicated in Table 1 and otherwise based on the assumptions listed in Table 4 . The overall RO specific OPEX, $L_{O, R O}$, was then determined taking account of the membrane replacement cost factor $L_{M} /(J t)$, analogous to MBR case.

Accordingly, the RO specific OPEX in $\$ . \mathrm{m}^{-3}$ follows a linear relation with the TDS in $\mathrm{g} / \mathrm{L}$ :

$$
L_{O, R O}=0.0134 \mathrm{TDS}+0.137
$$

\begin{tabular}{|c|c|c|c|c|c|c|c|}
\hline TDS, mg/L & $\begin{array}{c}\text { Power } \\
\text { kW }\end{array}$ & $\begin{array}{c}\text { Feed press. } \\
\text { bar }\end{array}$ & $\begin{array}{c}E_{L} \\
\mathrm{kWh} \cdot \mathrm{m}^{-3}\end{array}$ & $\begin{array}{c}\text { LChem,RO } \\
\text { \$. } \mathrm{m}^{-3}\end{array}$ & $\begin{array}{c}L_{M} /(J t) \\
\$ . m^{-3}\end{array}$ & $\begin{array}{l}\text { L'O,RO } \\
\text { S.m }{ }^{-3}\end{array}$ & $\begin{array}{l}\text { Lo,Ro } \\
\text { \$. } \mathbf{m}^{-3}\end{array}$ \\
\hline 422 & 286 & 8.0 & 0.686 & 0.0244 & 0.0148 & 0.093 & 0.108 \\
\hline 4182 & 453 & 12.7 & 1.087 & 0.0268 & 0.0148 & 0.136 & 0.151 \\
\hline 19322 & 1157 & 32.5 & 2.777 & 0.0264 & 0.0148 & 0.304 & 0.312 \\
\hline
\end{tabular}

Table 6. RO energy, chemicals and membrane replacement costs

Using the same software and extrapolating data trends to zero osmotic pressure while setting the flux to $6 \mathrm{LMH}$ (Table 4) for the FO membrane, the computed FO process $E_{L}$ is constant at $0.215 \mathrm{kWh} . \mathrm{m}^{-3}$. If pumping the draw solution is assumed to incur the same energy demand and the mean cost of chemical dosing $\left(L_{C h e m}=0.0271 \$ . \mathrm{m}^{-3}\right)$ and membrane replacement $\left(L_{M, F O} /(\mathrm{Jt})\right.$ $=0.119 \$ . \mathrm{m}^{-3}$ ) are added:

$$
L_{O, F O}=0.189
$$

\subsection{Overall treatment costs}

A summary of the correlations for the CAPEX and OPEX components of the costs for the relevant technologies indicate widely differing trends in CAPEX for the two different generic types of process (Table 7, Fig. 4). The MBR and OMBR have a greater economy of scale, associated with the nature of the process which is based on the construction of large tanks for 
both the process biology and the membranes. The RO and FO technologies have a much reduced economy of scale, as indicated by the shallower cost curve slope (Fig. 4).

For the base conditions considered, the OPEX is a linear function of the membrane air scour rate, process biological aeration demand, and the inverse flux for the MBR and OMBR, the process aeration being linearly related to the feed COD and TKN concentrations. For the fixed flux values of the RO and FO technologies, the OPEX is a function of the salinity (or TDS) for the RO but retains a constant value in the case of the FO. The FO OPEX is then most sensitive to the FO cost and replacement frequency.

Table 7. Specific CAPEX $\left(L_{C}, \$ /\left(\mathrm{m}^{3} \cdot \mathrm{d}^{-1}\right)\right.$ and $\operatorname{OPEX}\left(L_{O}, \$ / \mathrm{m}^{3}\right)$ correlations for all technologies

\begin{tabular}{|c|c|c|c|c|c|c|}
\hline \multirow[b]{2}{*}{ Technology } & \multicolumn{3}{|c|}{ CAPEX, $L_{C}, \$ /\left(\mathrm{m}^{3} \cdot \mathrm{d}^{-1}\right)$} & \multicolumn{3}{|c|}{ OPEX, $L_{O}, \$ / \mathrm{m}^{3}$} \\
\hline & $m$ & variable & $n$ & $m$ & variable & $c$ \\
\hline MBR, low TDS & 167 & $Q_{p, M B R}$ & -0.462 & 2.21 & $S A D_{m} / J$ & $0.164+E_{A, \text { biol }}$ \\
\hline MBR, high TDS & 139 & $Q_{p, M B R}$ & -0.424 & 2.21 & $S A D_{m} / J$ & $0.164+E_{A, b i o l}$ \\
\hline OMBR & 131 & $Q_{p, O M B R}$ & -0.412 & 2.21 & $S A D_{m} / J$ & $0.164+E_{A, b i o l}$ \\
\hline SWRO (high TDS) & 5.16 & $Q_{p, R O}$ & -0.0633 & $1.34 \times 10^{-5}$ & TDS & 0.137 \\
\hline BWRO (low TDS) & 2.42 & $Q_{p, R O}$ & -0.0804 & $1.34 \times 10^{-5}$ & TDS & 0.137 \\
\hline FO & 2.41 & $Q_{p, F O}$ & -0.0502 & - & - & 0.189 \\
\hline$E_{A, \text { boil }}$ & & & & 0.408 & COD & 0.050 \\
\hline
\end{tabular}

Flow $(Q)$ in $\mathrm{m}^{3} \cdot \mathrm{d}^{-1}: L_{C}=m Q_{p}{ }^{n}$; Concentrations (COD and TDS) in g.L.' ${ }^{-1}$; Flux $(J)$ in L.m ${ }^{-2} \cdot \mathrm{h}^{-1} ; S A D_{m}$ in $\mathrm{Nm}^{3} /\left(\mathrm{h} \cdot \mathrm{m}^{2}\right)$.

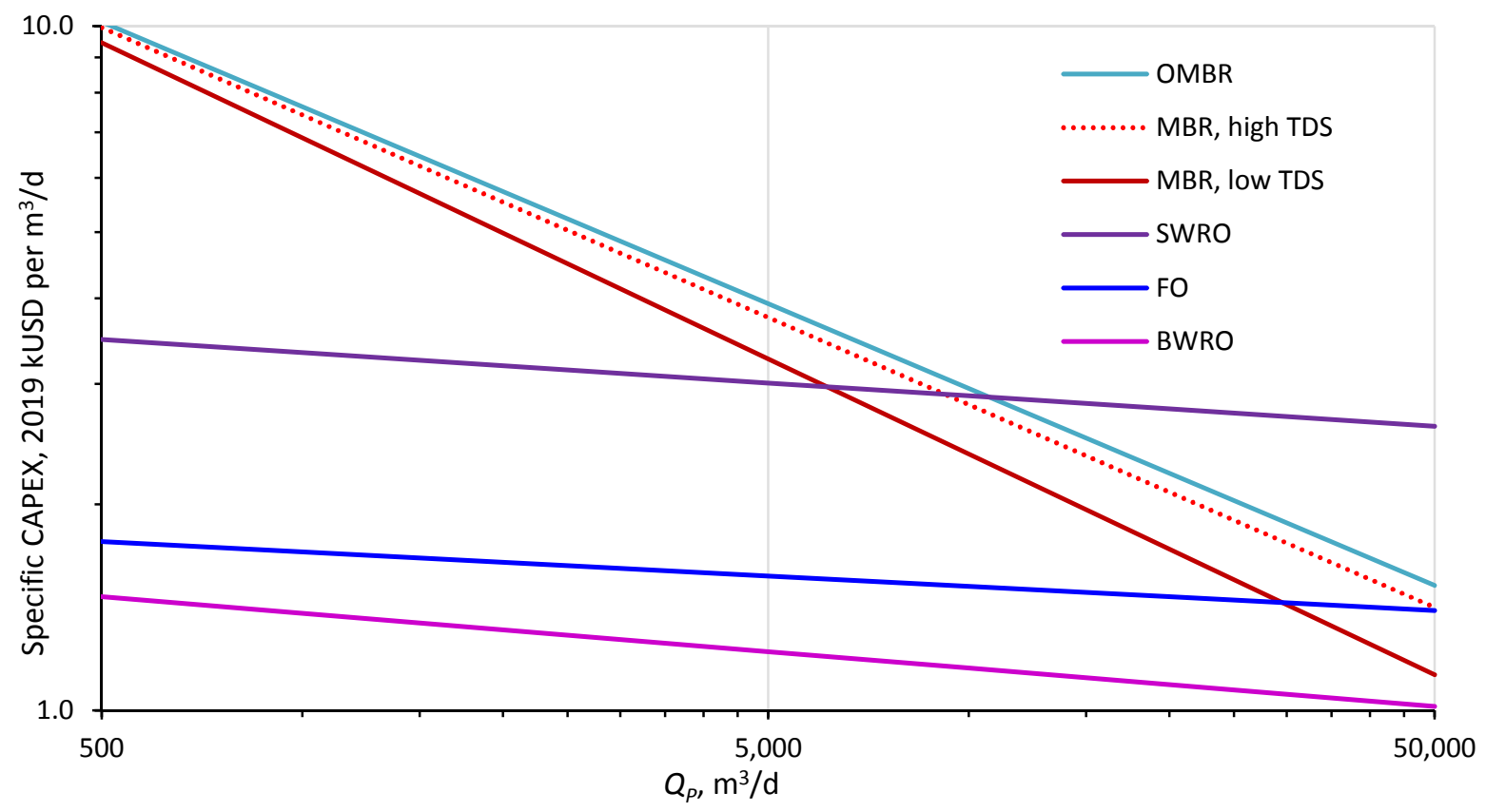

Figure 4. CAPEX trends with permeate flow.

The NPV is determined by combining the CAPEX and OPEX (Verrecht et al., 2010):

$$
\mathrm{NPV}=\sum_{t=0}^{t=n} \frac{\text { CAPEX }_{t=0}+\mathrm{OPEX}_{t}}{(1+\mathrm{D})^{t}}
$$

D being the discount factor (assumed to be $2 \%$ ) and $n$ the total plant life (or amortisation period), taken as 30 years. Annualising all scheduled OPEX, including membrane replacement, simplifies this equation: 


$$
\mathrm{NPV}=Q_{P} L_{C}+365 Q_{P} L_{O} \sum_{t=0}^{t=n} \frac{1}{(1+\mathbf{D})^{t}}=Q_{P}\left(L_{C}+8541 L_{O}\right)
$$

The normalised NPV values (NPV/QP, Fig. 5) demonstrate similar trends to those for the CAPEX (Fig. 4), indicating the widely accepted sensitivity of total costs to CAPEX. However, the relatively high cost of the FO membranes is reflected in the higher overall costs of the FO and OMBR technologies compared with low-salinity RO (i.e. BWRO) and MBR technologies respectively.

As with the CAPEX trends, the flow-normalised (or specific) NPV can be fitted to a power law $\left(\mathrm{NPV} / Q_{P}=m Q_{P}{ }^{n}\right.$ ), the $R^{2}$ values exceeding 0.995 in all cases other than for the OMBR (Table 8). These correlations can then be used to determine the specific NPV of the overall open loop treatment schemes based on a conversion of $95 \%$ for the MBR/OMBR and $75 \%$ for the RO/FO technologies.

For the FO and OMBR-based open loop systems two other cost factors are taken into account:

i. the cost penalty of the increased capacity of the downstream RO step, and

ii. the cost benefit of the reduced SED of this step due to the dilution afforded by the FO or OMBR.

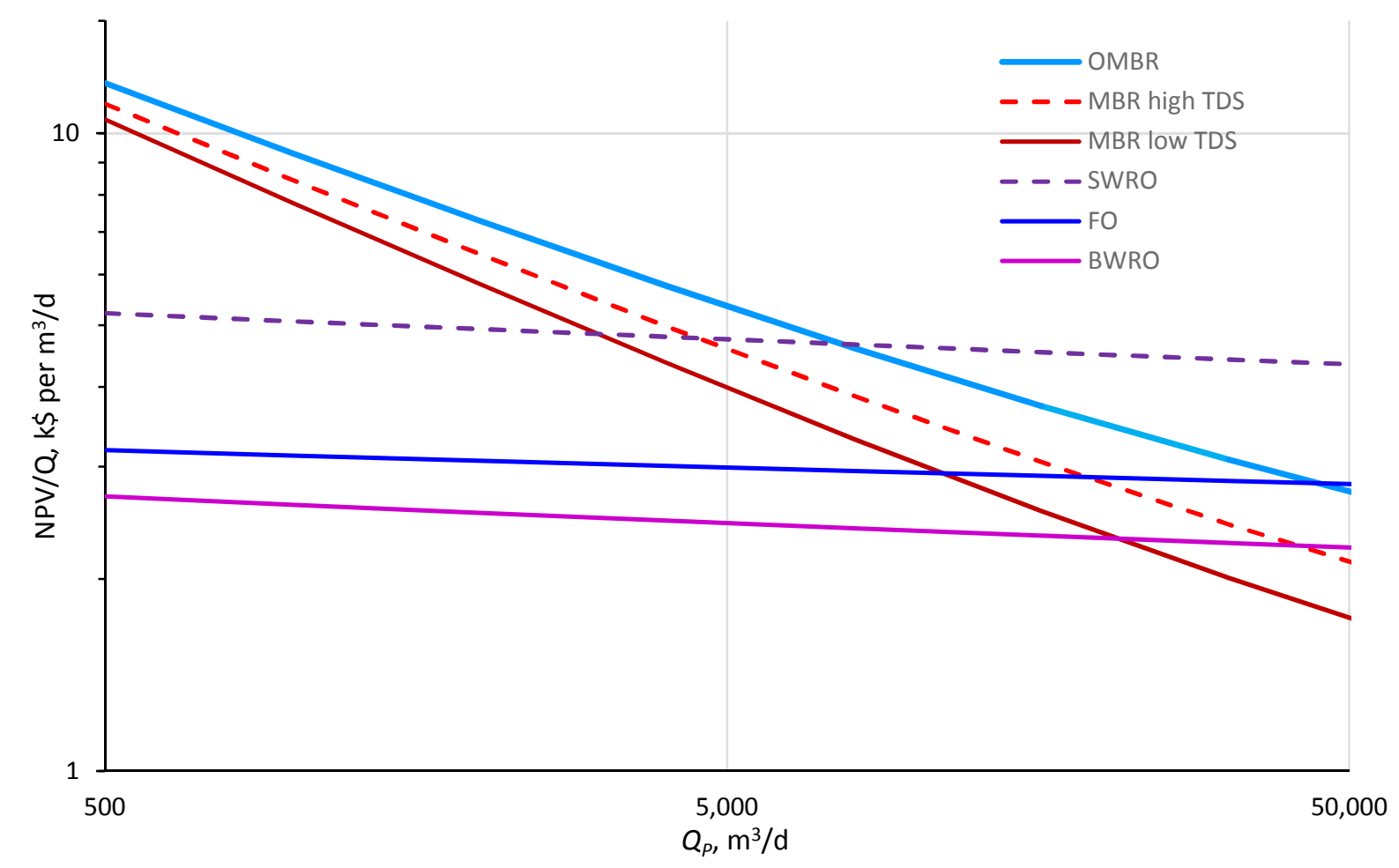

Figure 5. Normalised NPV vs. permeate flow rate for individual unit operations.

Table 8. Specific NPV $\left(\mathrm{NPV} / Q_{P}, \$ /\left(\mathrm{m}^{3} \cdot \mathrm{d}^{-1}\right)\right)$ correlations for all technologies

\begin{tabular}{l|cccc}
\hline & \multicolumn{4}{|c}{$\mathrm{NPV} / Q_{P}, \$ /\left(\mathrm{m}^{3} . \mathrm{d}^{-1}\right)$} \\
Technology & $m$ & variable & $n$ & $R^{2}$ \\
\hline MBR, low TDS & 103 & $Q_{p, M B R}$ & -0.377 & 0.996 \\
MBR, high TDS & 91.6 & $Q_{p, M B R}$ & -0.348 & 0.997 \\
OMBR & 69.3 & $Q_{p, O M B R}$ & -0.295 & 0.983 \\
SWRO (high TDS) & 6.67 & $Q_{p, R O}$ & -0.0396 & 0.999 \\
BWRO (low TDS) & 3.43 & $Q_{p, R O}$ & -0.0393 & 1.000 \\
\hline
\end{tabular}




\begin{tabular}{l|llll}
\hline FO & 3.74 & $Q_{p, F O}$ & -0.0261 & 1.000 \\
\hline
\end{tabular}

Subtracting (i) from (ii) above yields the net cost benefit $\Delta \varepsilon$ of saline dilution. $\Delta \varepsilon$ was calculated assuming a saline feedwater of $3.5 \mathrm{wt} \%$ salinity (i.e. normal seawater) and a $20 \%$ dilution of this stream by the FO or OMBR permeate. Under these conditions, the contribution of $\Delta \varepsilon$ to the overall NPV is small, but increases proportionally from $<1 \%$ to almost $10 \%$ as the permeate product flow increases from 500 to $50,000 \mathrm{~m}^{3} / \mathrm{d}$ (Fig. 6).

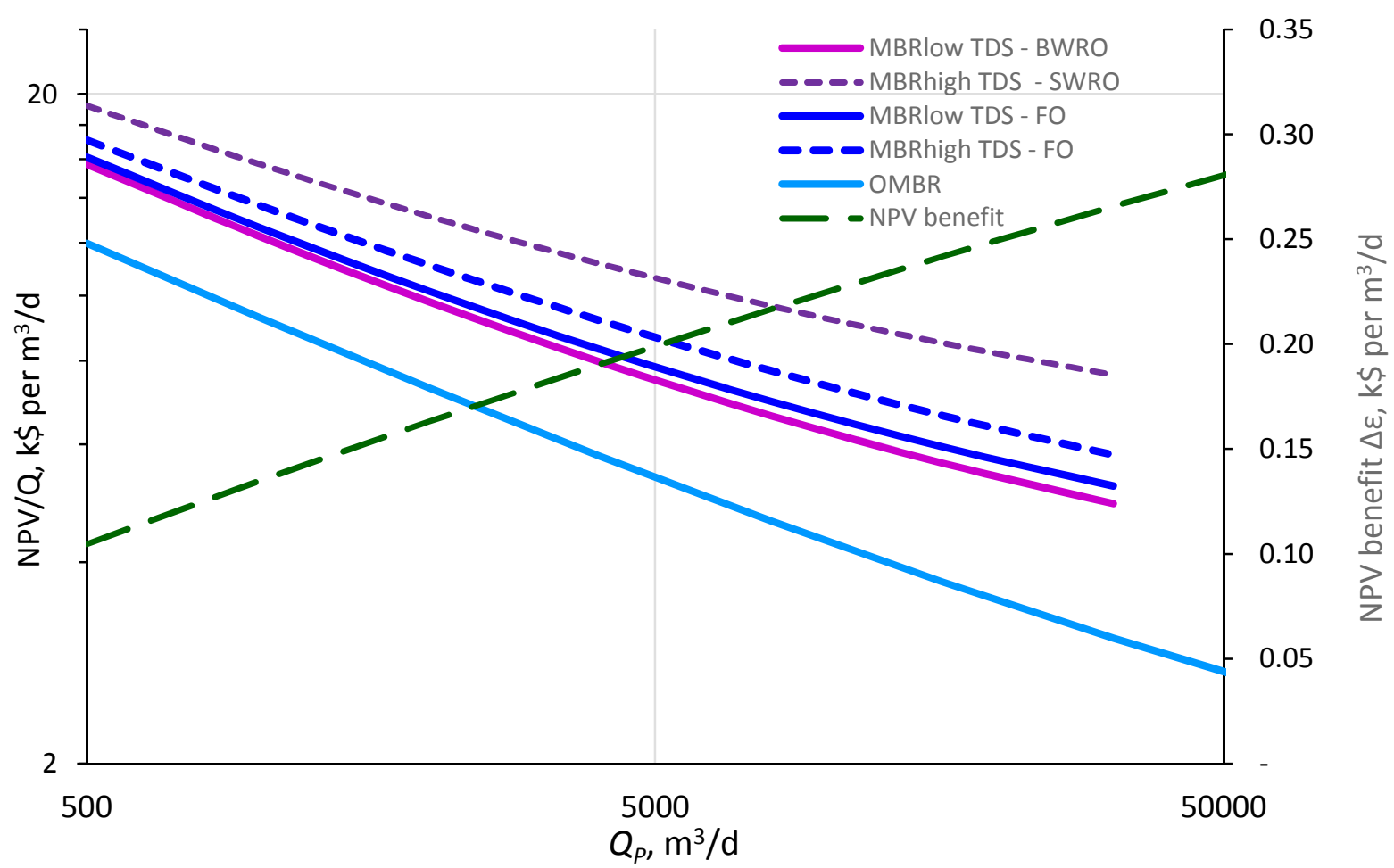

Figure 6. Normalised NPV vs. permeate flow rate for the overall wastewater reclamation schemes shown in Fig. 2.

Fig. 6 otherwise reveals that over the range of permeate product flows considered $(500-50,000$ $\left.\mathrm{m}^{3} \cdot \mathrm{d}^{-1}\right)$ and the base conditions indicated in Table 2 :

a. The MBR-FO option incurs an NPV 2-7\% higher than that of the conventional MBRBWRO option, the penalty increasing with increasing flow.

b. The same option provides an NPV benefit of $11-25 \%$ over the MBR-SWRO scheme used for a high feed TDS concentrations when higher RO pressures apply. This is in reasonable agreement with the outcomes of Teusner et al., 2017, who reported an overall $12 \%$ cost saving from implementing an open loop system for combined wastewater reclamation and seawater desalination.

c. The OMBR technology provides an NPV benefit of 24-39\% over the MBR-BWRO scheme.

Since there is evident significant variability in sustainable flux values reported from pilot and full-scale installations (Awad et al., 2019), this key parameter must subjected to a sensitivity analysis along with the membrane cost. Sensitivity can be demonstrated through correlating the $\%$ NPV/Q benefit compared with the classical MBR-RO scheme against the percentage change in these two base parameters. Accordingly, it is apparent that the NPV is more sensitive to 
membrane flux than to the cost of the material (Fig. 7). For example, halving the OMBR flux reduces the difference in the NPV benefit ( $\triangle \mathrm{NPV}$ ) of the OMBR over MBR-RO from $30 \%$ to $\sim 4 \%$ compared to a reduction to $26 \%$ for the same proportional decrease in membrane cost.

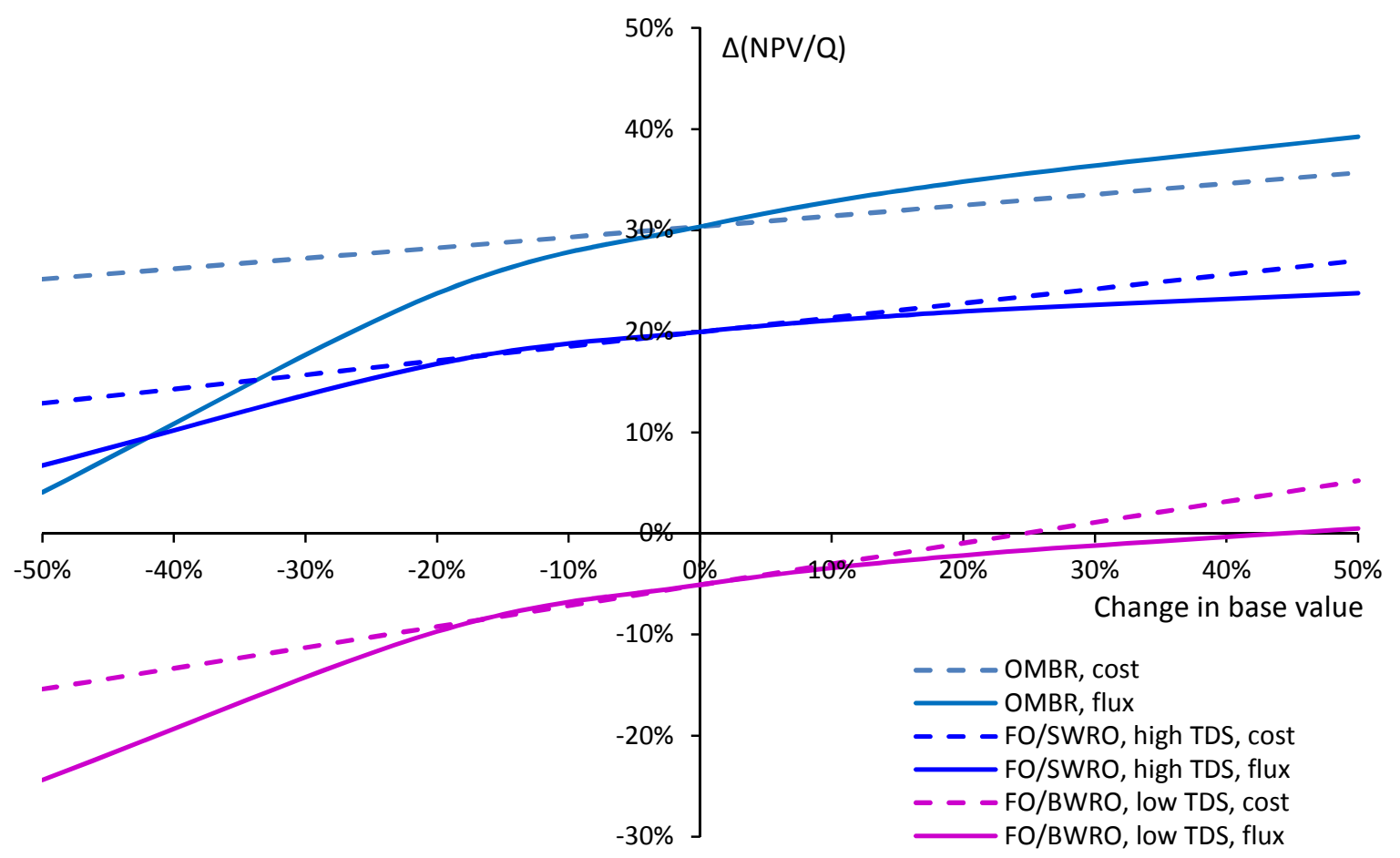

Figure 7. Sensitivity of the normalised NPV of the FO membrane-based wastewater reclamation schemes to membrane cost and operational flux: \% improvement in normalised NPV (Figs. 2b and 2c) compared with the classical MBR-RO scheme (Fig. 2a) vs. \%change in the membrane cost and operational flux base values, $Q_{P}=10,000 \mathrm{~m}^{3} \cdot \mathrm{d}^{-1}$.

A number of caveats apply to the analysis as a whole:

1. It is assumed that there is no replication of $\mathrm{CE}$ and other cost elements between the MBR and RO cost components, which have been captured from different literature sources and for which no consistent cost breakdown was provided. On the other hand, the very low exponent value for the RO CAPEX curves (Table 7) suggest little economy of scale and, by implication, little impact of extensive site-related CE costs.

2. The OMBR benefits from both being a single-stage process, significantly decreasing its CAPEX, and generating no brine waste stream. Against this, the effect of the $95 \%$ conversion is to increase the salinity in the reactor by a factor of 20, adversely impacting on the process microbiology and limiting its application to low-salinity wastewaters. Moreover, the subsuming of the dissolved salts with the sludge is likely to constrain the end disposal options of this stream, particularly if these include toxic metals.

3. The primary cost impact of increasing the conversion of the RO or FO step of the two-stage processes is to reduce the required size of the upstream MBR, reducing the CAPEX and thus the overall cost. However, increasing the conversion beyond $75 \%$ is likely to be practically challenged by membrane organic fouling and scaling, substantially increasing the OPEX. Previous studies have identified an optimum conversion value of $63 \%$ for simultaneous seawater desalination and wastewater purification (Cath et al., 2010).

4. Of the three treatment options, only the conventional MBR-RO process recovers water directly. The recovery of the value of the water, diluting a saline feed stream for downstream desalination by $\mathrm{RO}$, relies on the proximity of a saline stream requiring this desalination. 
Directing a saline feedwater to a wastewater treatment works to recover the value of the FO permeate would incur significant infrastructure costs which would need to be accounted for.

5. The accuracy of the calculated absolute NPV values relies on the provenance of the CAPEX data and the validity of the OPEX assumptions. A recent published CAPEX data set (World Bank, 2019) suggests greater economy of scale than the data set of Loutatidou et al. (Loutatidou et al., 2014) indicates for SWRO installations ( $n=-0.185$ vs. -0.0633$)$, yielding lower $L_{C, S W R O}$ values at higher flows. The World Bank (2019) report further suggests flow capacity dependency of OPEX, again leading to reduced specific costs at higher flows. This may reflect the importance of including labour costs, as noted elsewhere (Judd and Turan, 2019).

6. Notwithstanding the above limitations, the comparative normalised NPV values are likely to be valid since the assumptions made would have the same proportional impact across all three schemes. Thus, despite the conservative flux assumed for the OMBR, this technology appears to be more cost effective for recovering the value of the water than a two-stage MBR-FO process.

\section{$4 \quad$ Conclusions}

An empirical cost analysis of three alternative treatment schemes for recovering the value of wastewater can be conducted with reference to available capital cost (CAPEX) data, along with classical correlations and/or commercial CAD packages to compute operating cost (OPEX). Available data for the two established commercial membrane bioreactor (MBR) and reverse osmosis (RO) technologies can be used to estimate costs for the two novel forward osmosis (FO) and osmotic membrane bioreactor (OMBR) processes.

Assigning appropriate representative values for wastewater quality, process design and operation, and item costs reveals:

a. Flow capacity-normalised CAPEX and NPV follow an inverse power relationship $\left(\mathrm{R}^{2}>0.995\right)$ for all unit processes. The NPV-related exponent varies from low values $(0.025-$ 0.040 ) for $\mathrm{RO} / \mathrm{FO}$ to high values $(0.29-0.39)$ for $\mathrm{MBR} / \mathrm{OMBR}$, reflecting the greater economy of scale of the latter.

b. The value of the water recovered by the two extractive processes (FO and OMBR) is small if both the CAPEX penalty of increasing the downstream RO desalination plant size is taken into account in addition to the cost benefit of osmotic dilution of the feed. At flows below $30,000 \mathrm{~m}^{3} / \mathrm{d}$ the CAPEX penalty is more than two-thirds of the OPEX benefit, and the net NPV benefit of this component $(\Delta \varepsilon)$ equates to less than $10 \%$ of the total NPV benefit provided by the MBR-FO scheme compared to the MBR-BWRO.

c. At a permeate flow of $10,000 \mathrm{~m}^{3} \cdot \mathrm{d}^{-1}$ the OMBR offers a $30 \%$ NPV benefit (amortised over 30 years) over classical MBR-RO, and operates at a conversion of $95 \%$ overall compared with $\sim 75 \%$ for either the MBR-RO or MBR-FO process. Against this, the accumulation of dissolved solids in the process bioreactor imposes a constraint on the OMBR feedwater salinity.

d. At the same flow and for a high salinity feedwater, necessitating high-pressure SWRO desalination, the MBR-FO scheme has an NPV 20\% lower than that of the MBR-SWRO scheme. For a low-salinity feedwater the MBR-FO scheme offers no cost benefit over the classical MBR-BWRO scheme.

Whilst providing an apparent economic benefit, the full consequences of implementing the open loop system demands a consideration of the environmental impact through a life cycle analysis (LCA). 


\section{Acknowledgements}

This work was made possible by the support of a National Priorities Research Programme (NPRP) grant from the Qatar National Research Fund (QNRF), grant reference number NPRP10-0118-170191. The statements made herein are solely the responsibility of the authors. The authors would like to thank Dan Jerry Cortes from Qatar University and Arnold Janson from ConocoPhillips, Qatar for providing useful information for this paper.

\section{References}

Alejo, T., Arruebo, M., Carcelen, V., Monsalvo, V.M., Sebastian, V., 2017. Advances in draw solutes for forward osmosis: Hybrid organic-inorganic nanoparticles and conventional solutes. Chem. Eng. J. 309, 738-752.

Ansari, A.J., Hai, F.I., Price, W.E., Drewes, J.E., Nghiem, L.D., 2017. Forward osmosis as a platform for resource recovery from municipal wastewater - A critical assessment of the literature. J. Memb. Sci. 529, 195-206.

Awad, A.M., Jalab, R., Minier-Matar, J., Adham, S., Nasser, M.S., Judd, S., 2019. The status of forward osmosis technology implementation. Desalination 461, 10-21.

Blanco, L., Hermosilla, D., Blanco, Á., Swinnen, N., Prieto, D., Negro, C., 2016. MBR+RO Combination for PVC Production Effluent Reclamation in the Resin Polymerization Step: A Case Study. Ind. Eng. Chem. Res. 55, 6250-6259.

Blandin, G., Le-Clech, P., Cornelissen, E., Verliefde, A.R.D., Comas, J., Rodriguez-Roda, I., 2018. Can osmotic membrane bioreactor be a realistic solution for water reuse? npj Clean Water.

Blandin, G., Verliefde, A.R.D., Tang, C.Y., Le-Clech, P., 2015. Opportunities to reach economic sustainability in forward osmosis-reverse osmosis hybrids for seawater desalination. Desalination 363, 26-36.

Bogler, A., Lin, S., Bar-Zeev, E., 2017. Biofouling of membrane distillation, forward osmosis and pressure retarded osmosis: Principles, impacts and future directions. J. Memb. Sci. 542, 378-398.

Brepols, C., Schäfer, H., Engelhardt, N., 2010. Considerations on the design and financial feasibility of full-scale membrane bioreactors for municipal applications. Water Sci. Technol. 61, 2461-2468.

Cai, Y., Hu, X.M., 2016. A critical review on draw solutes development for forward osmosis. Desalination 391, 16-29.

Cashman, S., Mosely, J., 2016. Life cycle assessment and cost analysis of water and wastewater treatment options for sustainability: influence of scale on membrane bioreactor systems.

Cath, T.Y., Hancock, N.T., Lundin, C.D., Hoppe-Jones, C., Drewes, J.E., 2010. A multi-barrier osmotic dilution process for simultaneous desalination and purification of impaired water. J. Memb. Sci. 362, 417-426.

Chekli, L., Phuntsho, S., Kim, J.E., Kim, J., Choi, J.Y., Choi, J.S., Kim, S., Kim, J.H., Hong, S., Sohn, J., Shon, H.K., 2016. A comprehensive review of hybrid forward osmosis systems: Performance, applications and future prospects. J. Memb. Sci. 497, 430-449.

Choi, Y., Cho, H., Shin, Y., Jang, Y., Lee, S., 2015. Economic evaluation of a hybrid desalination system combining forward and reverse osmosis. Membranes. 6, 3.

Corzo, B., de la Torre, T., Sans, C., Escorihuela, R., Navea, S., Malfeito, J.J., 2018. Long-term evaluation of a forward osmosis-nanofiltration demonstration plant for wastewater reuse in agriculture. Chem. Eng. J. 338, 383-391. 
Côté, P., Buisson, H., Pound, C., Arakaki, G., 1997. Immersed membrane activated sludge for the reuse of municipal wastewater. Desalination 113, 189-196.

De Jager, D., Sheldon, M.S., Edwards, W., 2014. Colour removal from textile wastewater using a pilot-scale dual-stage MBR and subsequent RO system. Sep. Purif. Technol. 135, 135144.

DeCarolis, J., Adham, S., Pearce, W.R., Hirani, Z., Lacy, S., Stephenson, R., 2007. Cost Trends of Mbr Systems for Municipal Wastewater Treatment. Proc. Water Environ. Fed. 34073418.

Dialynas, E., Diamadopoulos, E., 2009. Integration of a membrane bioreactor coupled with reverse osmosis for advanced treatment of municipal wastewater. Desalination 238, 302311.

Farias, E.L., Howe, K.J., Thomson, B.M., 2014. Effect of membrane bioreactor solids retention time on reverse osmosis membrane fouling for wastewater reuse. Water Res. 49, 53-61.

Fleischer, E.J., Fonseca, A.D., Daigger, G.T., Canham, R.A., Broderick, T.A., Johnson, N.A., Lynch, D.P., 2010. Planning, Design, and Startup of a Large, Innovative Membrane Bioreactor Facility. Water Pract. Technol. 5.

Fritzmann, C., Lowenberg, J., Wintgens, T., Melin, T., 2007. State-of-the-art of reverse osmosis desalination. Desalination 216, 1-76.

Ge, Q., Ling, M., Chung, T.S., 2017. Draw Solutions for forward osmosis processes: Developments, challenges, and prospects for the fututre. J. Memb. Sci. 23, 1412-1423.

Gündoğdu, M., Jarma, Y.A., Kabay, N., Pek, T., Yüksel, M., 2018. Integration of MBR with $\mathrm{NF} / \mathrm{RO}$ processes for industrial wastewater reclamation and water reuse-effect of membrane type on product water quality. J. Water Process Eng.

Hancock, N.T., Black, N.D., Cath, T.Y., 2012. A comparative life cycle assessment of hybrid osmotic dilution desalination and established seawater desalination and wastewater reclamation processes. Water Res. 46, 1145-1154.

Holloway, R.W., Regnery, J., Nghiem, L.D., Cath, T.Y., 2014. Removal of trace organic chemicals and performance of a novel hybrid ultrafiltration-osmotic membrane bioreactor. Environ. Sci. Technol. 48, 10859-10868.

Holloway, R.W., Wait, A.S., Fernandes da Silva, A., Herron, J., Schutter, M.D., Lampi, K., Cath, T.Y., 2015. Long-term pilot scale investigation of novel hybrid ultrafiltrationosmotic membrane bioreactors. Desalination 363, 64-74.

Iglesias, R., Simón, P., Moragas, L., Arce, A., Rodriguez-Roda, I., 2017. Cost comparison of full-scale water reclamation technologies with an emphasis on membrane bioreactors. Water Sci. Technol. 75, 2562-2570.

Itokawa, H., Tsuji, K., Yamashita, K., Hashimoto, T., 2014. Design and operating experiences of full-scale municipal membrane bioreactors in Japan. Water Sci. Technol. 69, 10881093.

Johnson, D.J., Suwaileh, W.A., Mohammed, A.W., Hilal, N., 2018. Osmotic's potential: An overview of draw solutes for forward osmosis. Desalination 434, 100-120.

Judd, S., 2014. Industrial MBRs, 1st ed. Judd and Judd Ltd, Cranfield, UK.

Judd, S., \& Turan, F. 2019. Sidestream vs immersed membrane bioreactors: A cost analysis. Paper presented at the 91st Annual Water Environment Federation Technical Exhibition and Conference, WEFTEC 2018, 3722-3733.

Judd, S.J., 2017. Membrane technology costs and me. Water Res. 122, 1-9.

Judd, S.J., 2016. The status of industrial and municipal effluent treatment with membrane bioreactor technology. Chem. Eng. J. 305, 37-45.

Judd, S.J., 2006. The MBR Book Principles and Applications of Membrane Bioreactors in Water and Wastewater Treatment, 1st ed. Elsevier, UK.

Kim, J.E., Phuntsho, S., Chekli, L., Hong, S., Ghaffour, N., Leiknes, T.O., Choi, J.Y., Shon, 
H.K., 2017. Environmental and economic impacts of fertilizer drawn forward osmosis and nanofiltration hybrid system. Desalination 416, 76-85.

Korenak, J., Hélix-Nielsen, C., Bukšek, H., Petrinić, I., 2019. Efficiency and economic feasibility of forward osmosis in textile wastewater treatment. J. Clean. Prod. 210, 14831495.

Lawrence, P., Adham, S., Barrott, L., 2003. Ensuring water re-use projects succeed Institutional and technical issues for treated wastewater re-use. Desalination 152, 291298.

Liu, J., Wang, X., Wang, Z., Lu, Y., Li, X., Ren, Y., 2017. Integrating microbial fuel cells with anaerobic acidification and forward osmosis membrane for enhancing bio-electricity and water recovery from low-strength wastewater. Water Res. 110, 74-82.

Loutatidou, S., Chalermthai, B., Marpu, P.R., Arafat, H.A., 2014. Capital cost estimation of RO plants: GCC countries versus southern Europe. Desalination 347, 103-111.

Lu, Y., He, Z., 2015. Mitigation of Salinity Buildup and Recovery of Wasted Salts in a Hybrid Osmotic Membrane Bioreactor-Electrodialysis System. Environ. Sci. Technol. 49, 1052910535.

Luo, W., Hai, F.I., Price, W.E., Guo, W., Ngo, H.H., Yamamoto, K., Nghiem, L.D., 2016. Phosphorus and water recovery by a novel osmotic membrane bioreactor-reverse osmosis system. Bioresour. Technol. 200, 297-304.

Nguyen, T.-T., Kook, S., Lee, C., Field, R.W., In S. Kim, 2019. Critical flux-based membrane fouling control of forward osmosis: Behavior, sustainability, and reversibility. J. Memb. Sci. 570-571, 380-393.

Shahabi, M.P., McHugh, A., Ho, G., 2015. Environmental and economic assessment of beach well intake versus open intake for seawater reverse osmosis desalination. Desalination 357, 259-266.

She, Q., Wang, R., Fane, A.G., Tang, C.Y., 2016. Membrane fouling in osmotically driven membrane processes: A review. J. Memb. Sci. 87, 176-190.

Siddiqui, F.A., She, Q., Fane, A.G., Field, R.W., 2018. Exploring the differences between forward osmosis and reverse osmosis fouling. J. Memb. Sci. 565, 241-253.

Suwaileh, W.A., Johnson, D.J., Sarp, S., Hilal, N., 2018. Advances in forward osmosis membranes: Altering the sub-layer structure via recent fabrication and chemical modification approaches. Desalination 436, 176-201.

Tchobanoglous, G., Burton, F.L., David Stensel, H., 2003. Wastewater Engineering Treatment and Reuse, 4th ed. Metcalf \& Eddy Inc.

Teusner, A., Blandin, G., Le-Clech, P., 2017. Augmenting water supply by combined desalination/water recycling methods: an economic assessment. Environ. Technol. (United Kingdom) 38, 257-265.

Valladares Linares, R., Li, Z., Sarp, S., Bucs, S.S., Amy, G., Vrouwenvelder, J.S., 2014. Forward osmosis niches in seawater desalination and wastewater reuse. Water Res. 66, $122-139$.

Valladares Linares, R., Li, Z., Yangali-Quintanilla, V., Ghaffour, N., Amy, G., Leiknes, T., Vrouwenvelder, J.S., 2016. Life cycle cost of a hybrid forward osmosis - low pressure reverse osmosis system for seawater desalination and wastewater recovery. Water Res. 88, 225-234.

Verrecht, B., Maere, T., Nopens, I., Brepols, C., Judd, S., 2010. The cost of a large-scale hollow fibre MBR. Water Res. 44, 5274-5283.

Wan, C.F., Chung, T.S., 2018. Techno-economic evaluation of various RO+PRO and RO+FO integrated processes. Appl. Energy 212, 1038-1050.

World Bank, 2019. The Role of Desalination in an Increasingly Water-Scarce World. Washington. 
Wozniak, T., 2012. Comparison of a conventional municipal plant, and an MBR plant with and without MPE: A comparison of the environmental and financial performance of a conventional activated sludge (CAS) plant, membrane bio-reactor (MBR), and MBR treated with Nalco Membran. Desalin. Water Treat. 47, 341-352.

Xie, Z., Nagaraja, N., Skillman, L., Li, D., Ho, G., 2017. Comparison of polysaccharide fouling in forward osmosis and reverse osmosis separations. Desalination 402, 174-184.

Xu, W., Chen, Q., Ge, Q., 2017. Recent advances in forward osmosis (FO) membrane: Chemical modifications on membranes for FO processes. Desalination 419, 101-116.

Yangali-Quintanilla, V., Li, Z., Valladares, R., Li, Q., Amy, G., 2011. Indirect desalination of Red Sea water with forward osmosis and low pressure reverse osmosis for water reuse. Desalination 280, 160-166.

Young, T., Smoot, S., Peeters, J., Côté, P., 2013. When does building an MBR make sense? How variations of local construction and operating cost parameters impact overall project economics. Proc. Water Environ. Fed, 2013(8), 6354-6365. 